\title{
Effects of UV-, Visible-, Near-Infrared Beams in Three Therapy Resistance Case Studies of Fungal Skin Infections
}

\author{
Rozhin Penjweini $^{1,2}$, Soheila Mokmeli ${ }^{3}$, Klaus Becker ${ }^{1,4}$, Hans-Ulrich Dodt ${ }^{1,4}$, Saiedeh Saghafi ${ }^{1,2,4^{*}}$ \\ ${ }^{1}$ Department of Bioelectronics, Institute of Solid State Electronics, Vienna University of Technology, Vienna, Austria \\ ${ }^{2}$ Biophotonics Laboratory, Plasma-Physics Research Centre, Research Science Campus (IAU), Tehran, Iran \\ ${ }^{3}$ Iranian Medical Laser Associations, Tehran, Iran \\ ${ }^{4}$ Center for Brain Research, Medical University of Vienna, Section Bioelectronics, Vienna, Austria \\ Email: *saiedeh.saghafi@tuwien.ac.at
}

Received July 19, 2013; revised August 21, 2013; accepted September 23, 2013

Copyright (C 2013 Rozhin Penjweini et al. This is an open access article distributed under the Creative Commons Attribution License, which permits unrestricted use, distribution, and reproduction in any medium, provided the original work is properly cited.

\begin{abstract}
Fungal and bacterial diseases, directly infecting various parts of body, have received much attention in recent years. Bacterial infections, such as Tinea Pedis, Pityriasis versicolor and Mycetoma can secondarily occur in superficial fungal damaged skin. They often occur in immune compromised individuals including diabetics and patients with peripheral arterial diseases. Mycetoma infections can travel through the bloodstream affecting different organs. In this paper, we investigate the photo-inactivation of the pathogens causing Tinea Pedis, Pityriasis versicolor, and Mycetoma infections in three therapy resistant patients without photosensitizing drugs. We have used a combination of visible to near-infrared (VIS/NIR) laser beams in association with blue (B), red (R) and ultra-violet (UV) light emitted diodes (LEDs) with incident doses of $0.63-21.43 \mathrm{~J} / \mathrm{cm}^{2}$. These beams have minimum side effects on the normal part of the skin. According to the physicians' assessments, all case study patients achieved an observable progress such as decreases in inflammatory lesions, rapid process of wound healing and scars improvements. Side effects such as inflammation, crusting, or hypopigmentation were not observed. The presented irradiation protocol may be a valuable complementary treatment for patients suffering from fungal and bacterial skin infections.
\end{abstract}

Keywords: Fungal and Bacterial Infections; Coherent and Semi-Coherent Beams; Absorption Percentage

\section{Introduction}

Due to an increase in the number of therapy resistant patients with fungal and bacterial infections extensive attention has been focused towards alternatively noninvasive treatments in the recent years [1-4]. A secondary bacterial infection may occur in superficial fungal damaged skin such as Tinea Pedis, Pityriasis versicolor and Mycetoma [1-5]. Usually, immune compromised individuals, including diabetics and patients with peripheral arterial disease are suffering from these infections [5-8]. A fungal infection such as Mycetoma can spread via the bloodstream into different parts of the body causing a variety of symptoms [5-8]. In therapy resistance patients, efficient treatment of these fungal and bacterial diseases is a challenging task [2,4-8]. Conservative treatments for fungal and bacterial infections typically involve the oral application drugs that can cause strong side effects and their treatment success is controversial [2,9]. Symptoms ${ }^{*}$ Corresponding author. such as nausea, vomiting, diarrhea, stomach upset/pain, headache, serious allergic reactions or dizziness have been reported as sides-effects of oral medication with antibiotic and antimycotic drugs $[9,10]$. Patients with poor compliance related to gastric discomfort frequently are not effectively controlled by oral antimicrobial medication [10]. Oral antimicrobial medications are further contraindicated for patients with hepatotoxicity concerns $[2,10]$. Based on the effects of specific photons on cells, there is an alternative treatment, the so-called Photodynamic Therapy (PDT) $[2,11]$. In PDT, the tissues containing a particular photosensitizer are illuminated by laser beam. This irradiated tissue could be damaged through producing radicals of oxygen. The photosensitizer is applied into the tissue through injections or ointment. It has fluorescence spectra in the particular applied wavelengths [11-15]. The usage of the PDT method is still limited and some side effects were reported [11-14]. After PDT treatments, skin cells may become highly 
light sensitive, thus bright artificial lights containing related therapy wavelengths may cause a skin reaction even through the clothes [11-15]. Here, we suggested a non-invasive alternative photon treatment without usage of photosensitizers for therapy resistant patients suffering from Tinea Pedis, Pityriasis versicolor, or Mycetoma. Using absorption spectra analysis, we investigated the optical characteristics of normal and infected skin regions. From these data we derived suitable wavelengths for photo-destruction of the fungal pathogens with minimal side effects. We presented an alternative treatment protocol utilizing combinations of VIS-NIR laser beams in association with broadband beams of UV, B and RLEDs.

\section{Theory}

Considering the effects of non-ionizing electromagnetic waves on biological specimens, new methods in disinfection of microorganism can be developed [16,17]. Biological processes are influenced by coherent and noncoherent beams emitted from lasers and LEDs sources, respectively [18]. It occurs when sufficient light intensity reaches the target at the illuminated area $[18,19]$. By laser and LED illumination, local concentration, spatial orientation and physiology of microorganisms can be altered $[18,19]$. The intracellular temperature selectively may increase inducing distortions of intra-molecular target structures, and conformational changes of enzymes [16-21]. Some antimicrobial effects of irradiation appear, when cellular receptor proteins are excited due to light absorption. These photoexcitations can impair essential physiological signaling pathways, inducing cell death and apoptosis. It happens due to lesions in the genetic material leading to mutagenesis [22-25]. The wavelengths related to maximum light absorption can be determined by localizing the peaks in the absorption-spectrum. Thus, light sources which are best-possibly close to these determined wavelengths can be chosen.

It is reported that a linear polarized beam (coherent or non-coherent) in the VIS-IR range with an oscillating electric field $E$ can cause biological effects in cells through electrons oscillation inducement [16-19]. The underlying mechanism has been described in terms of photobiomodulation [26]. Photobiomodulation changes natural biochemical responses of the cell within the normal range of its function. Light can stimulate the cell's innate metabolic capacity to respond to a stimulus. The photobiomodulation may affect the cellular milieu in various disease conditions and promote spontaneous healing $[26,27]$. It is reported that illuminating microorganism with appropriate wavelengths can enhance Adenosine Triphosphate (ATP) synthesis by altering the mitochondrial membrane potential [16-18,26,27]. In addition, in photoexcited ATP, the charge distribution of the phosphate structure is changed, possibly causing a rapid reaction with other substrates. These reactions may increase Adenosine Diphosphate (ADP) as well as ATP synthesis [16,26,27]. The production of cytotoxic amounts of Reactive Oxygen Species (ROS) can be increased by irradiation leading to cell damage and cell death $[16,26,27]$.

\section{Materials and Methods}

\subsection{Case Reports}

This study is based on coherent and non-coherent light treatments of three therapy resistant adult patients with Tinea Pedis, Pityriasis versicolor and Mycetoma infections (e.g. Table 1). These patients were treated by different oral antifungal and antibacterial medications with negligible effects. Conventional treatments were terminated in all patients at least 1 month prior to initiating the irradiation processes. No additional treatments were applied during the study.

Case 1:

A 35-year-old woman, resident in Tehran, with widespread infection of Tinea Pedis (caused by Trichophyton rubrum) involving entire areas between her toes volunteered for fungus treatment using polychromatic/ monochromatic light irradiation. The individual areas between her toes showed an erythema covered with $15 \times 20 \mathrm{~mm}$ hyper pigmented plague with hyperkeratosis. She had been diagnosed as a patient with Tinea Pedis for over 20 years.

\section{Case 2:}

The second patient was a 42-year-old man, resident in Tehran, with Pityriasis versicolor (caused by Malassezia furfur), which is one of the most common superficial infections of the epidermis associated with alterations in pigmentation [28]. Because of this infection, multiple hyper pigmented maculas were appeared on the patient's skin. He had been diagnosed as a Pityriasis versicolor patient for 10 years.

Case 3:

A 44-year-old man, resident in Tehran, with Mycetoma infection on his legs (actinomycetoma caused by Actinomadura madura) was the third patient. He suffered from severe damaged edematous skin with multiple bullas and pustules with eryhthema and hyper pigmentation that some of them got necrosis and crust. As it has been reported in similar cases, deep thickening of the skin, resulted from edema, inflammation or infiltration was sensed in palpitation [4,6,29]. He had been diagnosed as a patient with Mycetoma for the last 20 years. 
Table 1. Summary of patients' details and outcome.

\begin{tabular}{ccccccc}
\hline Diagnosis & Sex & Age & Previous treatment & PMHx $^{\mathrm{a}}$ & Improvement & Side effect \\
\hline Tinea Pedis & Female & 35 & Topical imidazoles (topical creme) & Scald & Moderate & None \\
Pityriasis versicolor & Male & 42 & Itraconazole (oral antifungal drug) & gastric discomfort & Strong & None \\
Mycetoma & Male & 44 & $\begin{array}{c}\text { Trimethoprim-sulfamethoxazole } \\
\text { (Antimicrobial Tablets ) }\end{array}$ & Diabetes & Strong & None \\
\hline
\end{tabular}

${ }^{\mathrm{a}}$ Past medical History.

\subsection{Spectrophotometer Apparatus}

We used a CARY 500 scans-spectrophotometer to study and compare the optical properties of infected and normal skin. This spectrophotometer can measure reflection/transmission spectra over a large spectral range (UV-VIS-IR/175 - $3300 \mathrm{~nm}$ ). The relationship between transmission, reflection and absorption percentage of light through the medium can be approximated by [30]:

$$
A_{p}+R_{p}+T_{p} \cong 100
$$

where, $A_{p}, R_{p}$, and $T_{p}$ are absorption percentage, reflection percentage, and transmission percentage, respectively.

Figures 1-3 present comparisons of absorption spectra of the infected skins (e.g. Tinea Pedis, Pityriasis versicolor and Mycetoma) with absorption spectra of the normal skin (the so-called "index skin"). These spectra show the average absorption measured on three randomly chosen indexes (type III) and affected skin areas from each patient. Please note that the spectra of the cured skin after our treatment period and the spectra of the index skin are about identical for all three patients. Thus, the spectra of cured skin are not shown.

\subsection{Absorption Spectra Analysis}

It can be seen from Figures 1-3 that the maximum absorption, in all cases (including the "index skin") occurs in the range of 200 - $300 \mathrm{~nm}$ (UV). The strong absorption in the UV region is due to the existence of the amino acids in skin and microorganisms compounds in the infected areas [31]. The absorption percentage is dropped by $\sim 10 \%-12 \%$ in the range of $300-370 \mathrm{~nm}$ in the absorption spectra of both "index skin" and infected skin. The decrease in absorption percentage continues in the range of 370 - $1000 \mathrm{~nm}$. However, a few peaks have detected along the absorption spectrum in this range.

The absorption spectrum of the "index skin" of case study number-1 drops by 20\% between $370-600 \mathrm{~nm}$ (Figure 1(a)). In the range of $500-600 \mathrm{~nm}$, two peaks at $540 \mathrm{~nm}$ and $570 \mathrm{~nm}$ can be detected. These peaks occur due to haemoglobin and melanin compounds of the skin [32]. The absorption spectrum in the range of $620 \mathrm{~nm}$ to $1000 \mathrm{~nm}$ undergoes an additional drop by $~ 15 \%$. In Figure 1(b), in the range of $300-370 \mathrm{~nm}$, the absorption
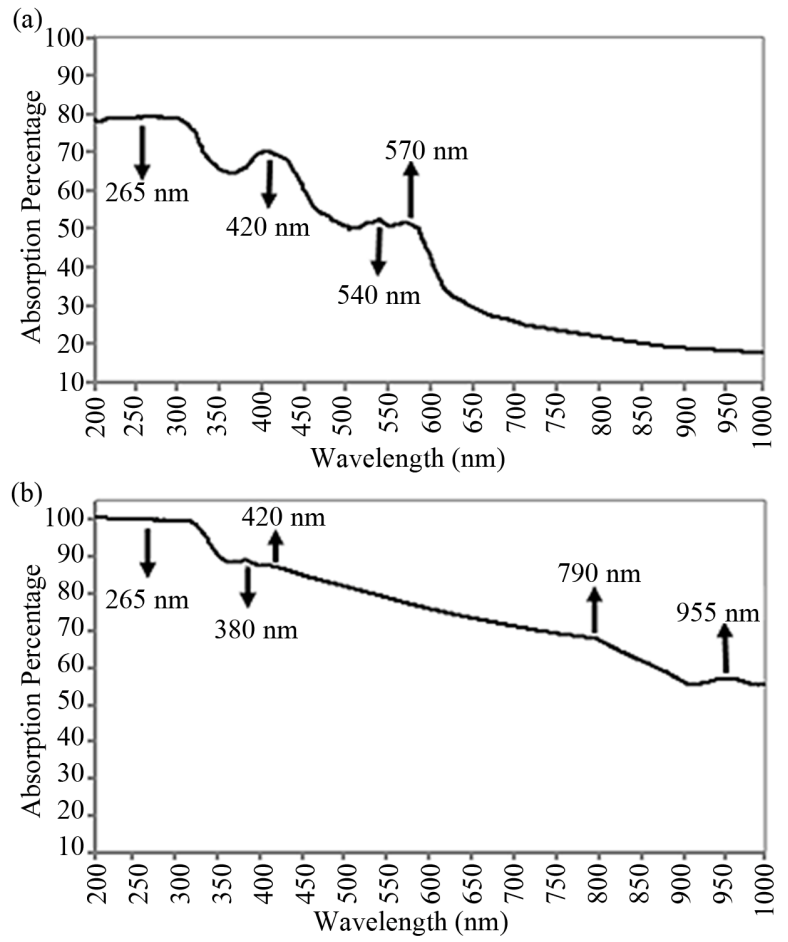

Figure 1. (a) The absorption spectrum of index skin (a woman with skin type III); (b) The absorption spectrum of skin affected by Tinea Pedis in the range of $200-1000 \mathrm{~nm}$.

percentage is decreased by $\sim 12 \%$. Between $370 \mathrm{~nm}$ to $400 \mathrm{~nm}$, a small peak centered at $380 \mathrm{~nm}$ is developed. In the range of 400 - $790 \mathrm{~nm}$ (VIS), the absorption spectrum decreases furthermore by $\sim 15 \%$. A sudden drop in absorption percentage appears in the next $100 \mathrm{~nm}$ ( 770 $900 \mathrm{~nm}$ ) follows by a sudden peak at $955 \mathrm{~nm}$.

Figures 2(a) and (b) present the absorption spectra of the "index skin" and infected area for the patient suffers from Pityriasis versicolor, case study number-2. In Figure 2(a), in the range of $370-600 \mathrm{~nm}$, the absorption percentage is decreased by $\sim 15 \%$. In the range of 500 $600 \mathrm{~nm}$, two peaks at $540 \mathrm{~nm}$ and $570 \mathrm{~nm}$ are detected. The decrease in absorption rate continues in the range of $620 \mathrm{~nm}$ to $1000 \mathrm{~nm}$ by $25 \%$. The absorption rate of wavelengths in the range of $300-370 \mathrm{~nm}$ drops by $~ 10 \%$ as shown in Figure 2(b). An immediate peak appears in the range of $370-410 \mathrm{~nm}$ centered at $380 \mathrm{~nm}$. The absorption percentage drops further by $\sim 25 \%$ in the range 
(a)

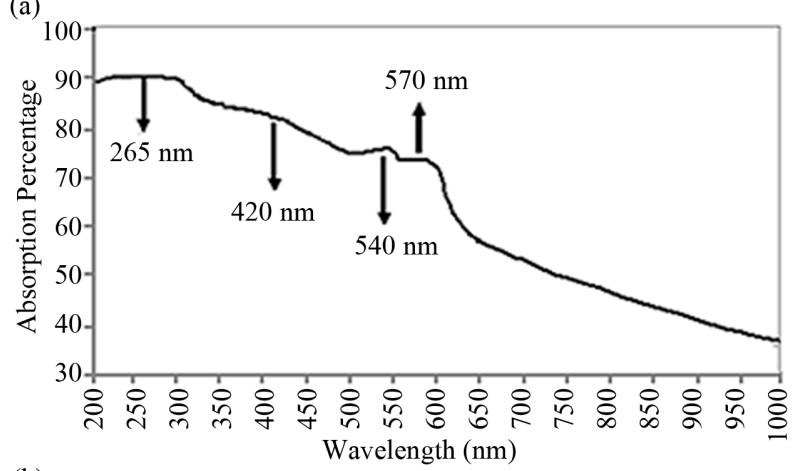

(b)

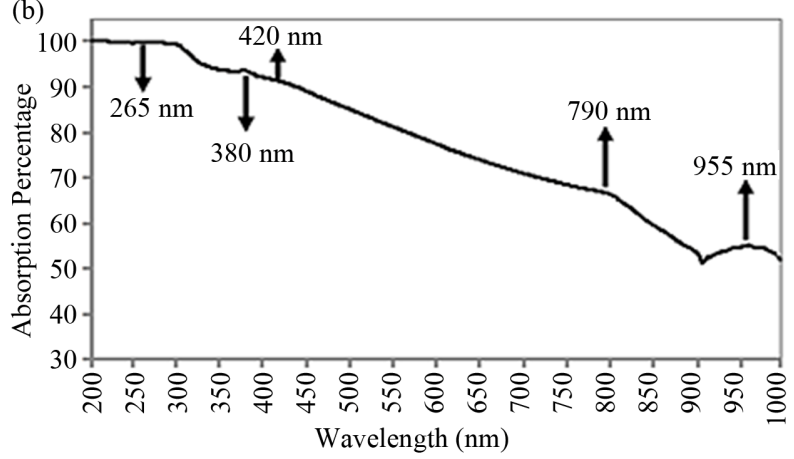

Figure 2. (a) The absorption spectrum of index skin (a man with skin type III); (b) The absorption spectrum of skin affected by Pityriasis versicolor in the range of 200 - 1000 nm.
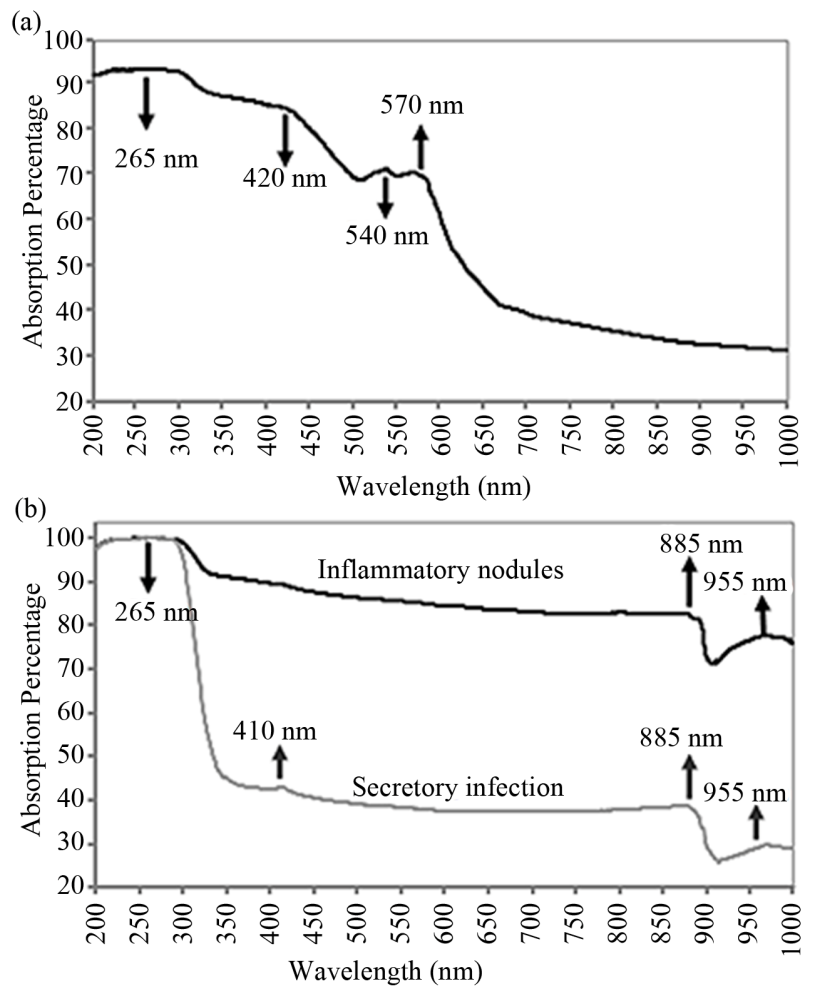

Figure 3. (a) The absorption spectrum of index skin (a man with skin type III); (b) The absorption spectrum of skin affected by Mycetoma in the range of $200-1000 \mathrm{~nm}$. of $400-770 \mathrm{~nm}$ (visible spectrum). In the next $130 \mathrm{~nm}$ (770 - $900 \mathrm{~nm}$ ), the absorption rate dropped further by $\sim 15 \%$ - $20 \%$ following by appearance of a peak at the range of 900 - $1000 \mathrm{~nm}$ centred at $955 \mathrm{~nm}$.

Figures 3(a) and (b) show the absorption spectra of the "index skin" and affected area (inflammatory nodules and its secretory infection) of the patient in case study number-3 suffers from Mycetoma. The absorption spectrum of the "index skin" of the case study number-3 drops by 25\% between $370-620 \mathrm{~nm}$. Two peaks due to haemoglobin and melanin at $540 \mathrm{~nm}$ and $570 \mathrm{~nm}$ can be detected. The absorption spectrum undergoes additional drop by $\sim 20 \%$ in the range of $620 \mathrm{~nm}$ to $1000 \mathrm{~nm}$. In Figure 3(b), between 300 - $370 \mathrm{~nm}$, the absorption percentage for inflammatory nodules drops by $\sim 10 \%$ while for secretory infection drops by $\sim 60 \%$. However, a small peak can be detected for the secretory infection at region between 395 - $430 \mathrm{~nm}$. A sudden drop in absorption rate ( 10\% - 15\%) occurs at 870 to $900 \mathrm{~nm}$. A peak between 900 - $1000 \mathrm{~nm}$ (centred at $955 \mathrm{~nm}$ ) is occurred.

In all cases, the well-defined protein receptors may partially be responsible for occurrence of some peaks. However, there are particular peaks that are just related to the infected skins and are absent in the absorption spectrum of related index skin. They can be the results of intrinsic electronic transitions within the microorganisms' protein receptors [33,34]. Therefore, lights with emissions overlapping the absorption peaks of the recaptors in the infected area may enable us to produce the photo-damage in the microorganisms [35-37]. For example, we can inclusively detect peaks centered at 380 and $410 \mathrm{~nm}$ for infected skin. There are two further peaks at the longer wavelengths (770 - $900 \mathrm{~nm}$ and $900-1000 \mathrm{~nm}$ ) in the infected area's spectrum. They can also be attributed to the absorption of microorganisms' photoreceptors.

\subsection{Light Sources Characterization}

Laser beam might be a strong effective tool in treatments of infected skin [38]. Furthermore, LEDs are suggested as safe light sources for medical treatments (e.g. wound healing, pain reduction, photo-rejuvenation) [38]. Hereby, considering the mentioned peaks of absorptions, a 100 $\mathrm{mW}$ second harmonics of Neodym-Dotierter YttriumAluminium-Granat, ND:YAG, laser emitting $532 \mathrm{~nm}$ beam, a $120 \mathrm{~mW}$ NIR diode laser emitting $780 \mathrm{~nm}$ beam, a $150 \mathrm{~mW}$ NIR diode laser emitting $980 \mathrm{~nm}$ beam, a $1050 \mathrm{~mW}$ array of Indium gallium nitride, InGaN, LEDs emitting beams in the range of 375 - 425 (centered at 400 $\mathrm{nm}$ ), a $440 \mathrm{~mW}$ array of bright B-LEDs emitting beam in the wavelength range of 460 - $465 \mathrm{~nm}$ and a $260 \mathrm{~mW}$ array of bright R-LEDs emitting beam in the wavelength range of 620 - $630 \mathrm{~nm}$ were used in this study. During the irradiation, infected areas were illuminated with these 
light sources, individually or in combination.

The output beams of our lasers are linearly polarized. The spatial intensity distribution of ND:YAG laser can be approximated by a Gaussian distribution and the diode lasers emit output beam with rectangular profile. Therefore, an optical configuration consists of two aspheric lenses with $27 \mathrm{~mm}$ focal length (facing each other) is used to convert laser output beam profiles into flattenedGaussian (enhanced top-hat) beams as shown in Figure 4(a). The intensity distribution is reshaped by the first aspheric lens and the second aspheric lens would correct the phase and spread the laser beam uniformly $[39,40]$.

Using an aperture, the LEDs output beam distributions were truncated. This truncated beam were impinged on a combination of a condenser-combination-lens with 16 $\mathrm{mm}$ focal length and a Plano-convex lens with $60 \mathrm{~mm}$ focal length to produce a semi flattened Gaussian distribution (see Figure 4(b)). All lenses have anti-reflector coating for visible range.

Finally, combined systems are mounted in a frame to make them suitable for therapy applications (Figures 5(a) and (b)). The spatial intensity distributions of the output beams of the units along the illuminating axis are measured using LaserCam-HRTM/Coherent as shown in Figure 5(c).

\subsection{Irradiation Protocol}

At the first stage of the irradiation process, lesions received $4.2 \mathrm{~J} / \mathrm{cm}^{2}$ incident doses of $532 \mathrm{~nm}$ beam. Then we illuminated the infected areas by light emitted from UV-A LED (centered at $400 \mathrm{~nm}$ ). The total incident dose during this phase of illumination was $0.63 \mathrm{~J} / \mathrm{cm}^{2}$. The illumination process was continued using a total incident dose of $9.34+16.36 \mathrm{~J} / \mathrm{cm}^{2}$ emitted from combined B-LED and NIR-Diode laser beams, respectively. The
B-LED emitted beam was in the range of 460 - $465 \mathrm{~nm}$ and the wavelength of the NIR-Diode laser used in this phase was $780 \mathrm{~nm}$. Finally, we illuminated the affected areas by a combination of red and infrared beams emitted from R-LEDs (wavelengths in the range of 620 - 630) and NIR-Diode laser emitting $980 \mathrm{~nm}$ beams. The total incident dose of this phase is $7.95+21.43 \mathrm{~J} / \mathrm{cm}^{2}$. The protocol of irradiation is summarized in Table 2.

During the treatment period, the patients were informed to report any adverse symptoms caused by irradiation. Two dermatologists evaluated clinical improvements, complete lesion and patient response rates one month after the last treatment following a blinded procedure. Initially, they compared the images of the infected areas obtained one month after treatment with the images taken one month prior to illumination. In the second assessment, self-evaluations of the patients regarding symptomatic improvements such as pain, itching and swelling reduction were analyzed. Figures 6-8 demonstrate significant improvements in all therapy resistant patients participating in our study. Skin photographs were obtained by an Olympus/E-10 4MP Digital Camera with $4 \times$ Optical Zoom before, during and one month after the final treatment session.

\section{Results and Discussion}

According to the physicians' assessment and follow-up procedure, all patients achieved observable and sustained improvements. Decrease in inflammatory lesions, rapid wound healing, and scars reductions are reported for all patients (Table 1 and Figures 6-8). None of the patients complained about any adverse effects except of mild sensations during the $532 \mathrm{~nm}$ irradiation and temporarily weak erythema. The symptoms completely disappeared

(a)
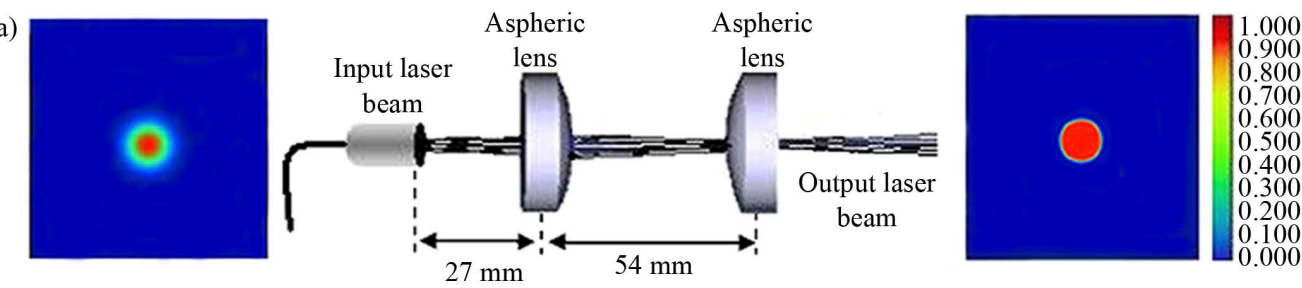

(b)
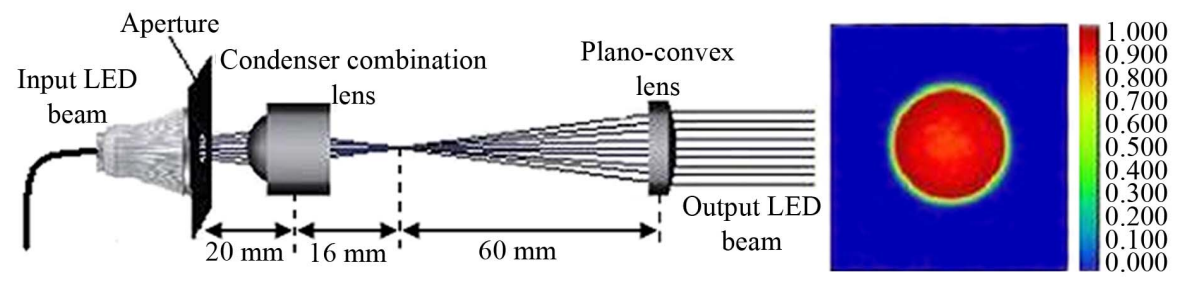

Figure 4. (a) An optical configuration consists of two aspheric lenses with 27 mm focal length to convert laser Gaussian beam profiles into flattened-Gaussian (enhanced top-hat); (b) An optical set up consists of an aperture; a condenser combination lens with $16 \mathrm{~mm}$ focal length and a Plano-convex lens of $60 \mathrm{~mm}$ focal length to collimate the LEDs beam. The set up produces a semi flattened Gaussian distribution of the LEDs beam. 
Table 2. Protocol of irradiation.

\begin{tabular}{|c|c|c|c|c|}
\hline Light source & Wavelength (nm) & Power density $\left(\mathrm{mW} / \mathrm{cm}^{2}\right)$ & Exposure time (s) & $I D\left(\mathrm{~J} / \mathrm{cm}^{2}\right)$ \\
\hline Second harmonics of ND:YAG & 532 & 1415 & 3 & 4.25 \\
\hline Combination of 10 UVA-LED & $375-425$ & 20.90 & 30 & 0.63 \\
\hline Combination of 22 B-LED and a NIR laser & $460-465 \& 780$ & $15.57 \& 27.27$ & 600 & $9.34 \& 16.36$ \\
\hline Combination of 13 R-LED and a NIR laser & $620-630 \& 980$ & $13.25 \& 35.71$ & 600 & $7.95 \& 21.43$ \\
\hline
\end{tabular}
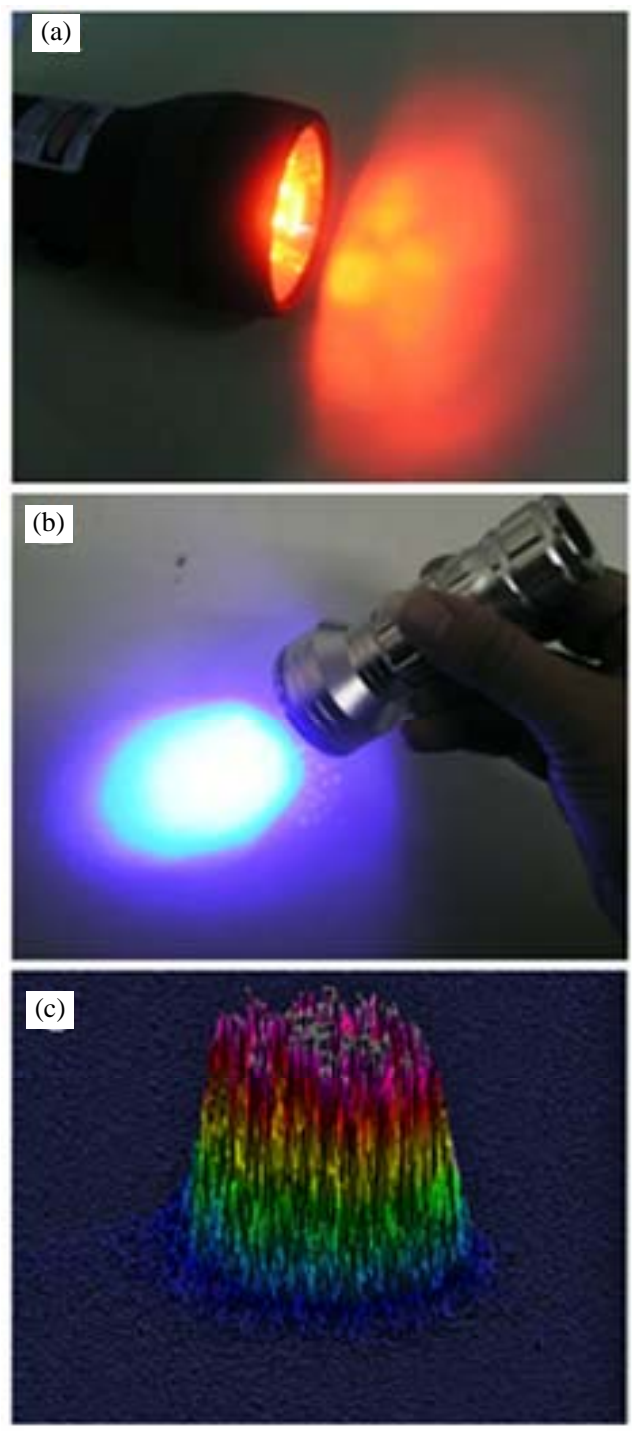

Figure 5. (a) and (b) Combined systems (lasers and LEDs) mounted in a frame to make them suitable for therapy applacations; (c) Three dimensional isometric plots of the combined lasers' and LEDs' beam profile distribution. The pictures show that the combined light sources have a flattened Gaussian distribution.

within 24 hours. During follow-up procedure (next three months), further side effects, such as inflammation, crusting, or hypopigmentation were not observed. Therefore, we have presented an effective irradiation protocol for antifungal and antibacterial treatment of three ther-

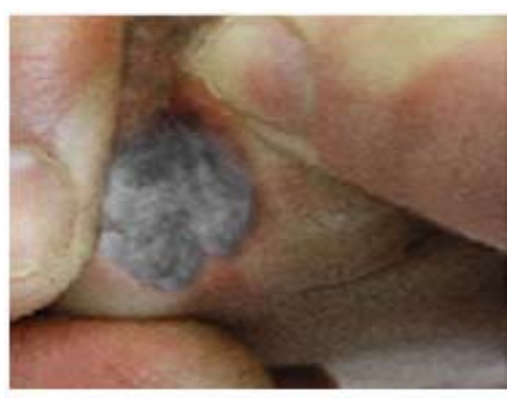

(a)

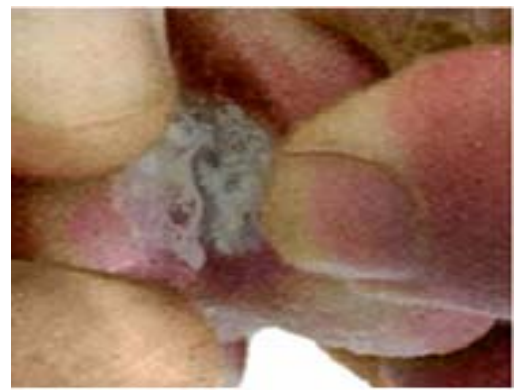

(b)

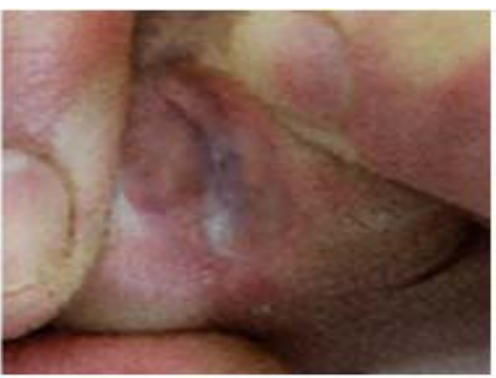

(c)

Figure 6. Patient 1: Widespread infection of Tinea Pedis involving all the areas between the toes. (a) The individual areas between the toes, demonstrate an erythema area covered with $15 \times 20 \mathrm{~mm}$ hyper pigmented plague with hyperkeratosis; (b) After 6 sessions of illuminations, the hyperkeratosis had improvement in some areas; (c) After 12 sessions of illuminations, hyperkeratosis had a moderate improvement.

apy resistant patients. The protocol relies on a combination of non-ionizing beams in the range of $375 \mathrm{~nm}-980$ nm. Since no photosensitizing drugs were applied, the risk of toxicological skin damage is very low [41,42]. The UV component as well as the combination of narrow-band blue light and NIR laser beam was applied 


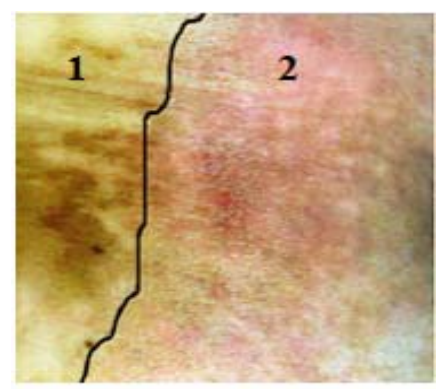

(a)

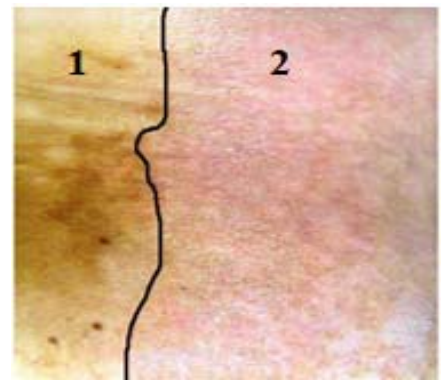

(b)

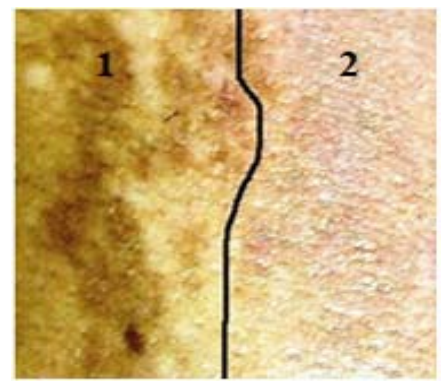

(c)

Figure 7. Patient 2: Multiple hyperpigmented macula were appeared on the patient's skin because of Pityriasis versicolor. In the pictures, 1 is the non-irradiated reference area and 2 is the irradiated area. (a) After 9 sessions of irradiation most pigmented lesions had a strong improvement; (b) The pigmented macula lesions were disappeared after two months; (c) One month after the last treatment, the pigmented lesions had strong improvements and the temporary weak erythema was disappeared. No side effects such as inflammation, crusting, or hypopigmentation were observed one month after the last treatment. Image in part $\mathrm{C}$ is taken with a higher zoom.

to stop inflammatory processes of the skin, by destroying the pathogenic fungi via photodamage [41,43-46]. This light combination can also enhance blood circulation and improve cells self-defense mechanism.

The combination of NIR/780 nm (longer wavelength with higher penetration depth and less scattering) with blue beam/460 - 465 nm (shorter wavelength with less penetration depth and high absorption) eradicates microorganism in the body as well as in the surface of skin. Since the second harmonics of ND:YAG beam can coagulate blood [42], it was applied to stop secretion of

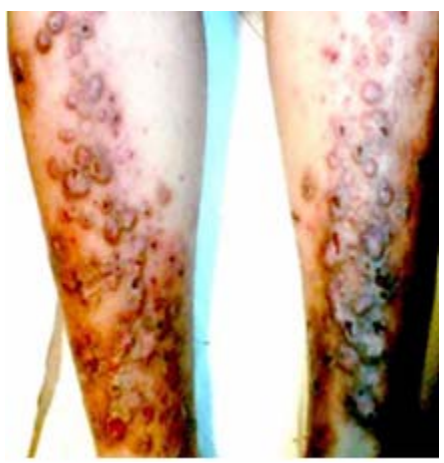

(a)

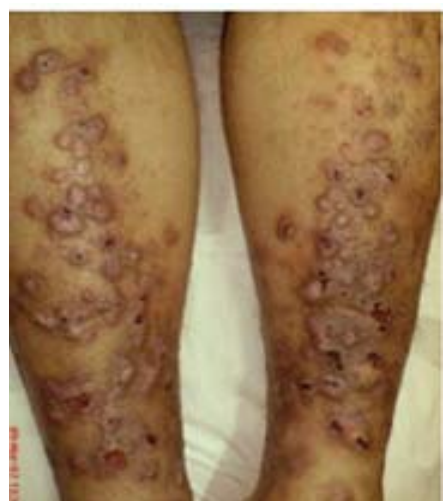

(b)

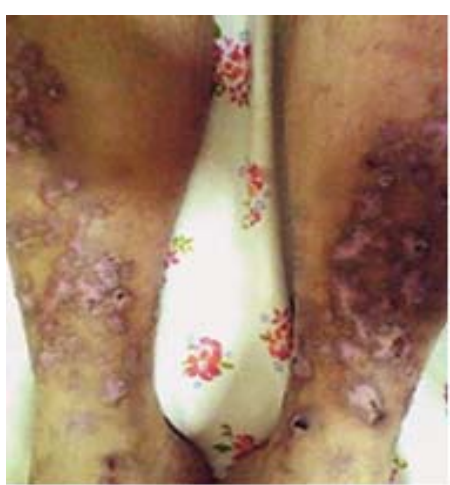

(c)

Figure 8. Patient 3: Mycetoma infection of Skin. (a) Before illumination, the infection shows sever damaged edematous skin with multiple bullas and pustules with eryhthema and hyperpigmentation that some of them got necrosis and crust. In palpitation deep thickening of the skin, resulted from edema, inflammation or infiltration was sensed; (b) A significant reduction in lesions observed after two months treatment; (c) One month after the last treatment, bullas and pustules disappeared. Most pigmented lesions had a strong improvement and most of the wounds healed. No side effects such as inflammation, crusting, or hypopigmentation were observed one month after the last treatment.

blood and wound liquid from open skin lesions, which are characteristic for fungal infections in an progressed state. The finally applied combinations of R-LED (625 $630 \mathrm{~nm})$ and NIR laser (980 nm) were shown to increase 
the blood flow in mesenteric microcirculation [47-49] and thus were applied to accelerate the healing of the damaged skin after the pathogen was eliminated. Furthermore, these combinations have further positive musculoskeletal effects as well as pain relieving effects.

\section{Summary}

Conventional medical treatments for fungal and bacterial infections in therapy resistant patients typically involve the use of orally applied antibiotic or antimycotic medications [2]. As a result, the standard drug treatment regimen is prolonged, and the appearance of drug-resistant strains has become more frequent $[2,10]$. In Mycetoma, surgical treatment is also an alternative therapeutic option if the patient's condition has not responded to oral treatment alone. This may cause multiple side effects [2, 50]. PDT has been suggested as a complementary treatment for therapy resistant patients [2,11-14]. However, the data on this study are still limited and in some cases, the aggravation rates are higher than with other methods [2,11-14]. Because of these drawbacks, an ongoing need for alternative treatment of recalcitrant Tinea Pedis, Pityriasis versicolor and Mycetoma infections is required. From a case study performed on three therapy-resistant patients we give evidence that fungal skin infections as Tinea Pedis, Pityriasis versicolor, and Mycetoma can be successfully treated by a combination of laser and LED irradiation in a wavelength range of $375-980 \mathrm{~nm}$. Since the developed therapy scheme does not need the application of photosensitizer, side effects are very low.

\section{Conclusion}

Laser Phototherapy comprising wavelengths in the range of 375 - $980 \mathrm{~nm}$ can be successfully applied in the treatment of various skin infections as Tinea Pedis, Pityriasis versicolor or Mycetoma. Since no photosensitizer is applied to the risk of side effects as phototoxic skin damage is very low.

\section{REFERENCES}

[1] C. Archer-Dubon, M. E. Icaza-Chivez, R. Orozco-Topete, E. Reyes, R. Baez-Martinez and S. Ponce de León, “An Epidemic Outbreak of Malassezia Folliculitis in Three Adult Patients in an Intensive Care Unit: A Previously Unrecognized Nosocomial Infection," International Journal of Dermatology, Vol. 38, No. 6, 1999, pp. 453456. http://dx.doi.org/10.1046/j.1365-4362.1999.00718.x

[2] J. W. Lee, B. J. Kim and M. N. Kim, "Photodynamic Therapy: New Treatment for Recalcitrant Malassezia Folliculitis," Lasers in Surgery and Medicine, Vol. 42, No. 2, 2010, pp. 192-196. http://dx.doi.org/10.1002/lsm.20857

[3] M. D. Richardson and D. W. Warnock, "Fungal Infection: Diagnosis and Management," 3rd Edition, Blackwell
Publishing Ltd., Oxford, 2003. http://dx.doi.org/10.1002/9780470755259

[4] A. Zarei Mahmoudabadi and M. Zarrin, "Mycetomas in Iran: A Review Article,” Mycopathologia, Vol. 165, No. 5, 2008, pp. 135-141. http://dx.doi.org/10.1007/s11046-007-9066-z

[5] A. O. A. Ahmed, A. M. El Sir, A. H. Fahal, E. E. Zijlstra, A. van Belkum and H. A. Verbrugh, "Unexpected High Prevalence of Secondary Bacterial Infection in Patients with Mycetoma,” Journal of Clinical Microbiology, Vol. 36, No. 3, 1998, pp. 850-851.

[6] M. O. A. Samaila, H. N. Mbibu and O. P. Oluwole, "Human Mycetoma,” Surgical Infections, Vol. 8, No. 5, 2007, pp 519-522. http://dx.doi.org/10.1089/sur.2006.052

[7] A. M. Kligman and J. J. Leyden, “The Interaction of Fungi and Bacteria in the Pathogenesis of Athlete's Food in Skin Microbiology," In: H. I. Maibach and R. Aly, Eds., Skin Microbiology, Springer-Verlag, New York, 1981, pp. 203-219.

[8] G. D. L. Smyth, “Fungal Infection in Otology,” British Journal of Dermatology, Vol. 76, No. 10, 2006, pp 425428.

http://dx.doi.org/10.1111/j.1365-2133.1964.tb14466.x

[9] H. A. Gallis, R. H. Drew and W. W. Pickard, "Amphotericin B: 30 Years of Clinical Experience," Reviews of Infectious Diseases, Vol. 12, No. 3, 1990, pp. 308-329. http://dx.doi.org/10.1016/S1201-9712(99)90038-3

[10] J. K. Aronson, "Meyler's Side Effects of Antimicrobial Drugs,” Elsevier, Amsterdam, 2010.

[11] E. G. de Oliveira Mima, A. C. Pavarina, L. N. Dovigo, C. E. Vergani, C. A. de Souza Costa, C. Kurachi, V. S. Bagnato and S. Paulo, "Susceptibility of Candida Albicans to Photodynamic Therapy in a Murine Model of Oral Candidosis," Oral Surgery, Oral Medicine, Oral Pathology, Oral Radiology, and Endodontology, Vol. 109, No. 3, 2010, pp. 392-401.

http://dx.doi.org/10.1016/j.tripleo.2009.10.006

[12] A. H. M. M. Arits, K. Mosterd, P. Nelemans, M. J. Rooij, G. A. Krekels, P. J. Quaedvlieg, P. A. F. van Neer, A. J. van Geest, J. J. Rijzewijk, M. R. Hendriks, B. A. Essers, P. M. Steijlen, A. Sommer and N. J. W. Kelleners-Smeets, "FC20 Three Non-Invasive Treatment Options for Superficial Basal Cell Carcinoma: Photodynamic Therapy versus Imiquimod Versus 5-Fluorouracil. TTOP-sBCC Trial,” Melanoma Research Vol. 20, 2010, p. e38. http://dx.doi.org/10.1097/01.cmr.0000382822.21243.19

[13] H. Ahmadieh, R. Taei, M. Soheilian, M. Riazi-Esfahani, R. Karkhaneh, A. Lashay, M. Azarmina, M. H. Dehghan and S. Moradian, "Single-Session Photodynamic Therapy Combined with Intravitreal Bevacizumab and Triamcinolone for Neovascular Age-Related Macular Degeneration,” BMC Ophthalmology, Vol. 7, No. 10, 2007, pp. 16. http://dx.doi.org/10.1186/1471-2415-7-10

[14] N. R. Rigual, K. Thankappan, M. Cooper, M. A. Sullivan, T. Dougherty, S. R. Popat, T. R. Loree, M. A. Biel and B. Henderson, "Photodynamic Therapy for Head and Neck Dysplasia and Cancer," Archives of OtolaryngologyHead and Neck Surgery, Vol. 135, No. 8, 2009, pp. 784788. http://dx.doi.org/10.1001/archoto.2009.98 
[15] C. H. Sibata, V. C. Colussi, N. L. Oleinick and T. J. Kinsella, "Photodynamic Therapy: A New Concept in Medical Treatment," Brazilian Journal of Medical and Biological Research, Vol. 33, No. 8, 2000, pp. 869-880. http://dx.doi.org/10.1590/S0100-879X2000000800002

[16] A. Amat, J. Rigau, R. W. Waynant, I. K. Ilev and J. J. Anders, "The Electric Field Induced by Light Can Explain Cellular Responses to Electromagnetic Energy: A Hypothesis of Mechanism," Journal of Photochemistry and Photobiology B: Biology, Vol. 82, No. 2, 2006, pp. 152-160. http://dx.doi.org/10.1016/j.jphotobiol.2005.10.001

[17] H. A. Sadafi, Z. H. Mehboodi and D. Sardari, “A Review of the Mechanisms of Interaction Between the Extremely Low Frequency Electromagnetic Fields and Human Biology,” PIERS, Cambridge, USA, 2006, pp. 99-103.

[18] A. N. Rubinov, "Physical Grounds for Biological Effect of Laser Radiation,” Journal of Physics D: Applied Physics, Vol. 36, No. 19, 2003, pp. 2317-2330. http://dx.doi.org/10.1088/0022-3727/36/19/002

[19] A. N. Rubinov, "Physical Mechanisms of Biological Effect of Coherent and Noncoherent Light," Stepanov Institute of Physics National Academy of Sciences of Belarus, Minsk, 2005. http://www.laser.nu/lllt/lllt_editorial13.htm

[20] T. Karu, L. Pyatibrat and G. Kalendo, "Molecular Mechanism of the Therapeutic Effect of Low-Intensity Laser Radiation," Journal of Photochemistry and Photobiology B: Biology, Vol. 27, No. 3, 1995, pp. 219-223. http://dx.doi.org/10.1016/1011-1344(94)07078-3

[21] R. P. Feynman, R. B. Leighton and M. Sands, "The Feynman Lectures on Physics," Addison-Wesley, Redwood City, 1963.

[22] H.-R. Park, O.-H. Park, H.-Y. Lee, J.-J. Seo and K.-M. Bark, "Photochemical Reaction of Nalidixic Acid in Methanol," Bulletin of the Korean Chemical Society, Vol. 24, No. 11, 2003, pp. 1618-1622. http://dx.doi.org/10.5012/bkcs.2003.24.11.1618

[23] S. Hashimoto and H. Akimoto, "UV Absorption Spectra and Photochemical Reactions of Simple Aromatic Hydrocarbons in the Cryogenic Oxygen Matrix,” The Journal of Physical Chemistry, Vol. 93, No. 2, 1989, pp. 571577. http://dx.doi.org/10.1021/j100339a017

[24] T. Karu, L. Pyatibrat and G. Kalendo, "Irradiation with He-Ne Laser Increases ATP Level in Cells Cultivated in Vitro," Journal of Photochemistry and Photobiology B: Biology, Vol. 27, No. 3, 1995, pp. 219-223. http://dx.doi.org/10.1016/1011-1344(94)07078-3

[25] T. Karu, "Photobiology of Low-Power Laser Effects," Health Physics, Vol. 56, No. 5, 1989, pp. 691-704. http://dx.doi.org/10.1097/00004032-198905000-00015

[26] M. Choi, S. Y. Na, S. Cho and J. H. Lee, "Low Level Light Could Work on Skin Inflammatory Disease: A Case Report on Refractory Acrodermatitis Continua,” Journal of Korean Medical Science, Vol. 26, No. 3, 2011, pp. 454-456. http://dx.doi.org/10.3346/jkms.2011.26.3.454

[27] V. Manteifel, L. Bakeeva and T. Karu, "Ultrastructural Changes in Chondriome of Human Lymphocytes after Ir- radiation with He-Ne Laser: Appearance of Giant Mitochondria," Journal of Photochemistry and Photobiology B: Biology, Vol. 38, No. 1, 1997, pp. 25-30. http://dx.doi.org/10.3346/jkms.2011.26.3.454

[28] M. D. Catterall, M. E. Ward and P. Jacobs, “A Reappraisal of the Role of Pityrosporum Orbiculare in Pityriasis Versicolor and the Significance of Extracellular Lipase,” Journal of Investigative Dermatology, Vol. 71, No. 6, 1978, pp. 398-401. http://dx.doi.org/10.1111/1523-1747.ep12557535

[29] H. Abbasher, A. E. M. Ahmed, A. H. Fhal, M. Abdulla, A. Sidig, K. Awad and E. M. Ahmad, "Cervical Cord Compression Secondary to Mycetoma Infection,” Sudanese Journal of Public Health, Vol. 2, No. 2, 2007, pp. 112115.

[30] S. Saghafi, R. Penjweini, K. Becker, K. W. Kratky and H.-U. Dodt, "Investigating the Effects of Laser Beams (532 and $660 \mathrm{~nm}$ ) in Annihilation of Pistachio Mould Fungus Using Spectrophotometry Analysis,” Journal of the European Optical Society-Rapid publications, Vol. 5, 2010, Article ID: 10033s. http://dx.doi.org/10.2971/jeos.2010.10033s

[31] M. Leo and L. Nollet, "Handbook of Food Analysis,” In: L. M. L. Nollet, Ed., Physical Characterization and $\mathrm{Nu}$ trient Analysis, CRC Press, 2004, 912 p.

[32] G. Zonios, J. Bykowski and N. Kollias, “Skin Melanin, Hemoglobin, and Light Scattering Properties Can be Quantitatively Assessed in Vivo Using Diffuse Reflectance Spectroscopy,” Journal of Investigative Dermatology, Vol. 117, No. 6, 2001, pp. 1452-1457. http://dx.doi.org/10.1046/j.0022-202x.2001.01577.x

[33] J. M. Wells, R. J. Cole and J. W. Kirksey, "Emodin, a Toxic Metabolite of Aspergillus Wentii Isolated from Weevil-Damaged Chestnuts," Applied Microbiology, Vol. 30, No. 1, 1975, pp. 26-28.

[34] G. Kobayashi, T. Nakamura, H. Ohmachi, A. Matsuoka, T. Ochiai and K. Shikama, "Yeast Flavohemoglobin from Candida Norvegensis; Its Structural, Spectral, and Stability Properties,” The Journal of Biological Chemistry, Vol. 277, No. 3, 2002, pp. 42540-42548. http://dx.doi.org/10.1128/EC.3.3.715-723.2004

[35] A. Kawada, Y. Aragane, H. Kameyama, Y. Sangen and T. Tezuka, “Acne Phototherapy with a High-Intensity, Enhanced, Narrow-Band, Blue Light Source: An Open Study and in Vitro Investigation,” Journal of Dermatological Science, Vol. 30, No. 2, 2002, pp. 129-135. http://dx.doi.org/10.1016/S0923-1811(02)00068-3

[36] W. P. Baugh and W. D. Kucaba, "Nonablative Phototherapy for Acne Vulgaris Using the KTP 532 nm Laser," Dermatologic Surgery, Vol. 31, No. 10, 2005, pp. 12901296. http://dx.doi.org/10.1111/j.1524-4725.2005.31205

[37] S. H. Tseng, P. Bargo, A. Durkin and N. Kollias, "Chromophore Concentrations, Absorption and Scattering Properties of Human Skin in-Vivo,” Optics Express, Vol. 17, No. 17, 2009, pp. 14599-14617. http://dx.doi.org/10.1111/j.1524-4725.2005.31205

[38] T. I. Karu, "Photobiology of Low-Power Laser Therapy," Taylor \& Francis, Boca Raton, 1989.

[39] B. Braunecker, R. Hentschel and H. J. Tiziani, “Advanced 
Optics Using Aspherical Elements,” SPIE Press, Bellingham, 2008.

[40] S. A. Viznyuk and A. T. Sukhodol'skii, "Rectification of the Intensity Distribution of Gaussian Beams Using Aspheric Lenses," Soviet Journal of Quantum Electronics, Vol. 20, No. 2, 1990, pp. 167-170. http://dx.doi.org/10.1070/QE1990v020n02ABEH005576

[41] T. Kubasova, M. Horvath, K. Kocsis and M. Fenyo, "Effect of Visible Light on Some Cellular and Immune Parameters,” Immunology and Cell Biology, Vol. 73, No. 3, 1995, pp. 239-244. http://dx.doi.org/10.1038/icb.1995.39 http://sensolitesopron.hu/sites/default/files/evidenciapdf/5 .pdf

[42] Z. Al Timimi, M. S. Jaafar and M. Z. Mat Jafri, "Photodynamic Therapy and Green Laser Blood Therapy," Global Journal of Medical Research, Vol. 11, No. 5, 2011, pp. 23-28.

[43] K. Veena, M. Ramaiah, G. K. Vanita, T. S. Avinash and V. P. Vaidya, "Synthesis of Symmetrical and Asymmetrical Azines Encompassing Naphtho[2,1-b]furan by a Novel Approach,” E-Journal of Chemistry, Vol. 8, No. 1, 2011, pp. 354-360. http://dx.doi.org/10.1155/2011/784932

[44] E. Shnitkind, E. Yaping, S. Geen, A. R. Shalita and W. L. Lee, "Anti-Inflammatory Properties of Narrow-Band Blue Light,” Journal of Drugs in Dermatology, Vol. 5, No. 7, 2006, pp. 605-610.

[45] P. Papageorgiou, A. Katsambas and A. Chu, "Phototherapy with Blue $(415 \mathrm{~nm})$ and Red $(660 \mathrm{~nm})$ Light in the Treatment of Acne Vulgaris,” British Journal of Dermatology, Vol. 142, No. 5, 2000, pp. 973-978. http://dx.doi.org/10.1046/j.1365-2133.2000.03481.x

[46] N. Fournier, K. Fritz and S. Mordon, "Use of Nonthermal Blue (405- to 420-nm) and Near-Infrared Light (850- to 900-nm) Dual-Wavelength System in Combination with Glycolic Acid Peels and Topical Vitamin C for Skin Photorejuvenation,” Dermatologic Surgery, Vol. 32, No. 9, 2006, pp. 1140-1146. http://dx.doi.org/10.1111/j.1524-4725.2006.32251.x

[47] Y. Maegawa, T. Itoh, T. Hosokawa, K. Yaegashi and M. Nishi, "Effects of Near-Infrared Low-Level Laser Irradiation on Microcirculation," Lasers in Surgery and Medicine, Vol. 27, No. 5, 2000, pp 427-437. http://dx.doi.org/10.1002/1096-9101(2000)27:5<427::AI D-LSM1004>3.0.CO;2-A

[48] J. K. Barton, D. P. Popok and J. F. Black, "Thermal Analysis of Blood Undergoing Laser Photocoagulation," IEEE Journal of Selected Topics in Quantum Electronics, Vol. 7, No. 6, 2001, pp. 936-943. http://dx.doi.org/10.1109/2944.983297

[49] H. T. Whelan, R. L. Smits, E. V. Buchman, N. T. Whelan, S. G. Turner, D. A. Margolis, V. Cevenini, H. Stinson, R. Ignatius, T. Martin, J. Cwiklinski, A. F. Philippi, W. R. Graf, B. Hodgson, L. Gould, M. Kane, G. Chen and J. Caviness, "Effect of NASA Light Emitting Diode Irradiation on Wound Healing," Journal of Clinical Laser Medicine \& Surgery, Vol. 19, No. 6, 2001, pp. 305-314. http://dx.doi.org/10.1089/104454701753342758

[50] P. Loulergue, A. Hot, E. Dannaoui, A. Dallot, S. Poirée, B. Dupont and O. Lortholary, "Short Report: Successful Treatment of Black-Grain Mycetoma with Voriconazole," The American Journal of Tropical Medicine and Hygiene, Vol. 75, No. 6, 2006, pp. 1106-1107. 